Original Research Article

\title{
Prescription pattern of antiepileptic drugs in indoor patients at tertiary care hospital in Haryana, India
}

\author{
Arvind Narwat*, Vivek Sharma
}

Department of Pharmacology, Pandit Bhagwat Dayal Sharma Post Graduate Institute of Medical Sciences, Rohtak, Haryana, India

Received: 02 January 2018 Accepted: 29 January 2018

*Correspondence to: Dr. Arvind Narwat, Email: arvindnarwat16@ gmail.com

Copyright: (C) the author(s), publisher and licensee Medip Academy. This is an openaccess article distributed under the terms of the Creative Commons Attribution NonCommercial License, which permits unrestricted noncommercial use, distribution, and reproduction in any medium, provided the original work is properly cited.

\begin{abstract}
Background: Epilepsy is a challenging medical problem in India with an annual incidence of 27.27 per 100,000 population and prevalence of 572.8 per 100,000. People with epilepsy require prolonged treatment and monitoring. The main goal in the treatment of epilepsy should be adequate control of seizures, without causing any life-threatening reactions due to the medications. This study was done to get an insight into the prescription pattern of anti-epileptic drugs (AEDs) in different types of epilepsy.
\end{abstract}

Methods: A prospective study was carried out for six months (Feb to June 2016) in admitted patients in super speciality ward (Lala Shyam Lal) in neurology department of PGIMS, Rohtak, Haryana. The prescription data of 100 patients of seizures was analysed.

Results: Idiopathic generalised epilepsy was commonest type of epilepsy (42\%) and sodium valproate was the commonest drug prescribed for its treatment $(66.66 \%)$ followed by phenytoin $(23.33 \%)$ Symptomatic epilepsy was second commonest seizure $(30 \%)$ and phenytoin $(60 \%)$ was the commonest drug prescribed for it followed by sodium valproate (30\%). Common adverse effects associated with anti-epileptic drugs (AEDs) were nausea, drowsiness, weight gain, diplopia and ataxia.

Conclusions: Idiopathic generalized epilepsy was the commonest type of epilepsy recorded and sodium valproate was the commonest prescribed drug.

Keywords: Anti epileptic drugs, ADRs, Drug prescription, Epilepsy, IRUD, INRUD

\section{INTRODUCTION}

Epilepsy is a common and chronic neurologic disorder worldwide. The risk of having epilepsy at some point in average life span of any individual varies between $2 \%$ $5 \% .^{1}$ In India also epilepsy is a challenging medical problem with an annual incidence of 27.27 per 100,000 population and prevalence of 572.8 per $100,000 .^{2}$ People with epilepsy require prolonged treatment and monitoring. The overall aim in treating epilepsy should be complete control of seizures, without causing any untoward reaction due to the medication. A large number of drugs are currently available for the treatment of epilepsy.
Older/conventional drugs like phenytoin, carbamazepine, valproic acid and ethosuximide are commonly used as first line drugs. They are relatively less expensive than the newer antiepileptics. Drugs like gabapentin, lamotrigine, vigabatrin, topiramate, tiagabine and zonisamide are the newer ones and currently used as add-on or alternative therapy and have lesser or few adverse effects. ${ }^{3,4}$ Seizure control may be achieved by mono-therapy in about $80 \%$ of the patients, with the other $20 \%$ requiring two to three AEDs. Monotherapy is normally the first line of treatment, as it has less drug interactions and side effects, lower cost, better tolerability, medication adherence, and quality of life but poly-therapy is often required for patients with multiple seizure types or refractory disease. 
WHO estimates that at least $50 \%$ of all medicines are used irrationally. In developing countries where $20-50 \%$ of health budgets are spent on drugs and other health commodities, irrational medicines use has been documented to contribute to patient morbidity and mortality, increase individual and government spending, as well as reducing confidence in the health care system. It can take the form of self medication, misuse and underuse of drugs, polypharmacy, unnecessary use of antibiotics and injections, as well as inappropriate prescribing as per clinical guidelines. ${ }^{5}$ WHO and the International Network of Rational Use of Drugs (INRUD) have developed a set of drug prescribing indicators to be used as measures of prescribing performance in primary care. ${ }^{5}$ To the our best knowledge, only few studies have been carried out till date in tertiary care measuring the Index of rationale use of drugs (IRUD). Measured values could be used as benchmarking among health care facilities and as a baseline for ongoing monitoring of the quality of drug prescribing. So this study would shed light on prescription pattern of antiepileptic drugs in tertiary care hospital.

\section{METHODS}

This was a prospective, observational study which was carried out for six months (February to June 2016) in admitted patients in super speciality ward (Lala Shyam Lal) in neurology department of PGIMS, Rohtak, Haryana. The prescription data of 100 patients of seizures was finally analysed.

\section{Data analysis}

The patient demographic data, WHO prescribing indicators (average number of medicines prescribed per patient encounter, percentage of drugs prescribed by generic name, percentage of encounters with an antibiotic prescribed, percentage of encounters with an injection prescribed and percentage of medicines prescribed from the NEML) and pharmacological classes of medicines prescribed were analyzed.

\section{IRUD}

Each of the five prescribing indicators has an optimal index of 1 (Table 1) the closer to 1 the calculated index is, the more rational prescribing is considered to be. The index of polypharmacy was measured by the percentage of nonpolypharmacy prescriptions. In this study, those prescriptions with three or less medicines where considered as nonpolypharmacy. The generic name index and essential medicine index were measured by the percentage of drugs prescribed by generic name and from the NEML respectively. The index of rational antibiotic prescribing was defined as dividing the optimal level (30\%) by the percentage of prescriptions including antibiotic. The index of safety injection was calculated by dividing the optimal level $(10 \%)$ by the percentage of prescriptions including the injection. The IRDP, which has a maximum value of 5 , can then be calculated by adding the indices.

Table 1: WHO/ INRUD- drug prescribing indicators.

\begin{tabular}{|lll|}
\hline Prescribing indicators & $\begin{array}{l}\text { Optimal } \\
\text { level }(\%)\end{array}$ & $\begin{array}{l}\text { Optimal } \\
\text { index }\end{array}$ \\
\hline $\begin{array}{l}\text { Percentage of non- } \\
\text { polypharmacy prescriptions }\end{array}$ & $\leq 3$ & 1 \\
\hline $\begin{array}{l}\text { Percentage of drugs precribed } \\
\text { by Generics }\end{array}$ & 100 & 1 \\
\hline $\begin{array}{l}\text { Percentage of Prescriptions } \\
\text { including antibiotics }\end{array}$ & $\leq 30$ & 1 \\
\hline $\begin{array}{l}\text { Percentage of Prescriptions } \\
\text { including injections }\end{array}$ & $\leq 10$ & 1 \\
\hline $\begin{array}{l}\text { Percentage of drugs } \\
\text { prescribed from NEML/ }\end{array}$ & 100 & 1 \\
\hline $\begin{array}{l}\text { Formulary } \\
\text { Drug prescribing performance scoring = 0 to 5 }\end{array}$ \\
\hline
\end{tabular}

\section{RESULTS}

In this study, prescription data of 100 patients was analysed out of which 55 patients were male whereas 45 patients were female (Figure 1). Patients were in age group of 18 to 65 years.

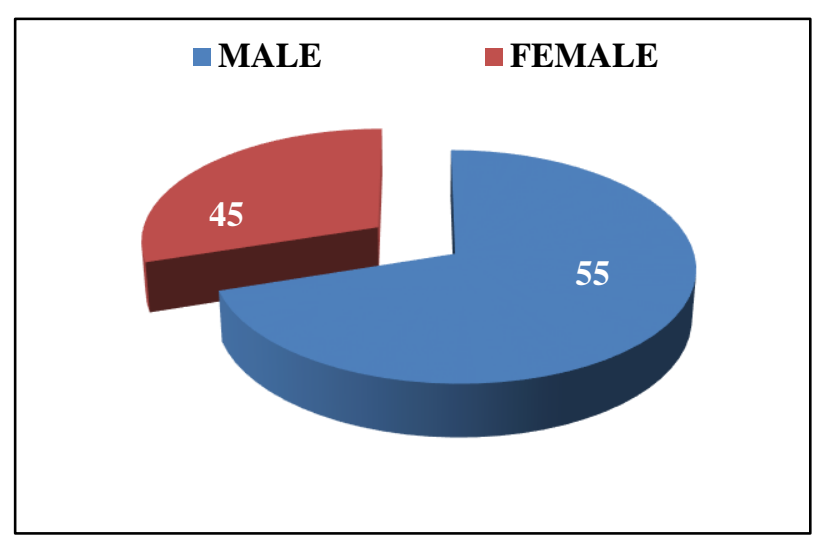

Figure 1: Total number of patients.

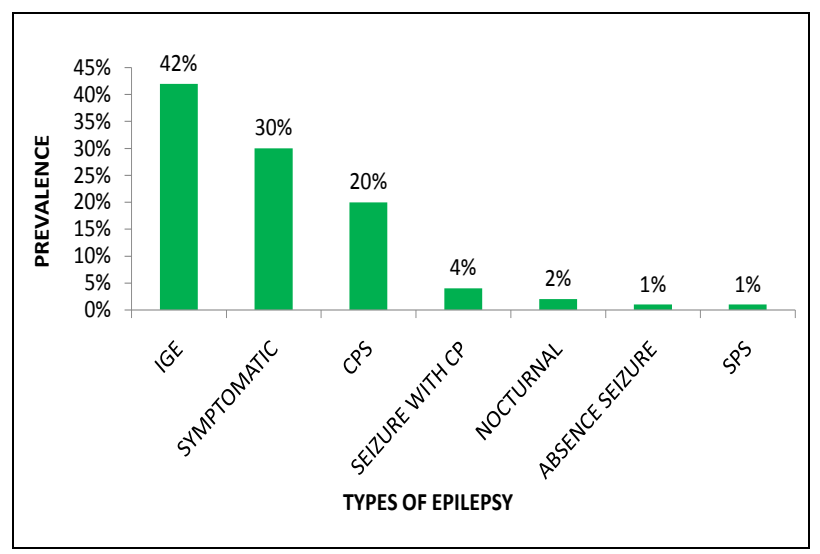

Figure 2: Types of epilepsy. 
A total of 186 drugs were prescribed in total 100 prescriptions. So average drugs prescribed per prescription was 1.86 drugs.

Commonest type of epilepsy in this study was idiopathic generalised epilepsy (Figure 2).

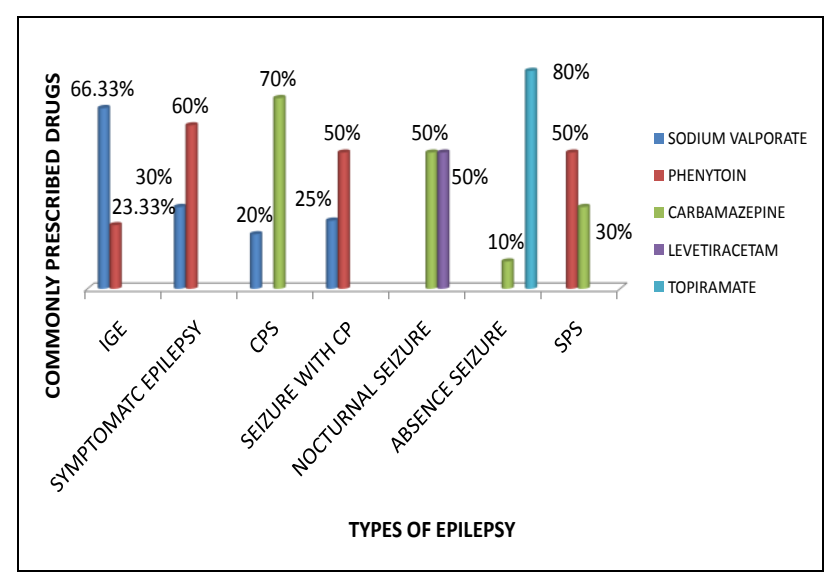

Figure 3: Commonly prescribed drugs in epilepsy.

Table 2: Other drugs prescribed in epilepsy.

\begin{tabular}{|l|}
\hline Drugs \\
\hline 1. Clobazam \\
\hline 2. Clonazepam \\
\hline 3. Oxcarbazepine \\
\hline
\end{tabular}

Table 3: Types of therapy in 100 patients of epilepsy.

\begin{tabular}{|lll|}
\hline $\begin{array}{l}\text { Types of therapy } \\
\text { Monotherapy (single }\end{array}$ & $\begin{array}{l}\text { Number of } \\
\text { patients }\end{array}$ & $\begin{array}{l}\text { Percentage } \\
(\%)\end{array}$ \\
\hline $\begin{array}{l}\text { AED) } \\
\text { Dual drug therapy }\end{array}$ & 59 & $59 \%$ \\
\hline Triple therapy & 36 & $36 \%$ \\
\hline Polytherapy & 2 & $3 \%$ \\
\hline
\end{tabular}

Table 4: Brand name vs generic name prescriptions.

\begin{tabular}{|l|l|}
\hline $\begin{array}{l}\text { Brand name (\% of } \\
\text { patients) }\end{array}$ & $\begin{array}{l}\text { Generic name ( } \% \text { of } \\
\text { patients) }\end{array}$ \\
\hline 75 & 25 \\
\hline
\end{tabular}

Out of 100 patients of epilepsy, 59 patients received monotherapy. $44.9 \%$ of patients received sodium valproate, $30.6 \%$ of patients received phenytoin and $10.20 \%$ of patients received carbamazepine. 36 patients were on Dual anti-epileptic drugs. The combination consisted of carbamazepine with clobazam or clobazam with clonazepam or clobazam with valproate. $3 \%$ of patients received triple anti-epileptic drugs namely combination of clobazam, clonazepam and valproate or combination of phenytoin, clobazam and valproate. Polytherapy with 4 drugs namely carbamazepine, clobazam, levetiracetam and Valproate was advocated in $2 \%$ of patients (Table 3 ).

Table 5: Prescribing indicators in this study.

\begin{tabular}{|c|c|c|}
\hline $\begin{array}{l}\text { Prescribing } \\
\text { indicators }\end{array}$ & $\begin{array}{l}\text { Optimal } \\
\text { level }(\%)\end{array}$ & $\begin{array}{l}\text { Optimal Index } \\
\text { calculated in } \\
\text { this study }\end{array}$ \\
\hline $\begin{array}{l}\text { Percentage of non- } \\
\text { polypharmacy } \\
\text { prescriptions }\end{array}$ & $\leq 3 \%$ & $\begin{array}{l}186 / 100=1.86 \\
\Rightarrow 1\end{array}$ \\
\hline $\begin{array}{l}\text { Percentage of drugs } \\
\text { prescribed by } \\
\text { Generics }\end{array}$ & $100 \%$ & $\Rightarrow \begin{array}{l}25 \% \\
0.25\end{array}$ \\
\hline $\begin{array}{l}\text { Percentage of } \\
\text { Prescriptions } \\
\text { including antibiotics }\end{array}$ & $\leq 30 \%$ & $\begin{array}{l}10 \% \\
\Rightarrow 1\end{array}$ \\
\hline $\begin{array}{l}\text { Percentage of } \\
\text { Prescriptions } \\
\text { including injections }\end{array}$ & $\leq 30 \%$ & $\begin{aligned} & 08 \% \\
\Rightarrow & 1\end{aligned}$ \\
\hline $\begin{array}{l}\text { Percentage of drugs } \\
\text { prescribed from } \\
\text { NEML/ Formulary }\end{array}$ & $100 \%$ & $\begin{aligned} & 90 \% \\
\Rightarrow & 0.9\end{aligned}$ \\
\hline
\end{tabular}

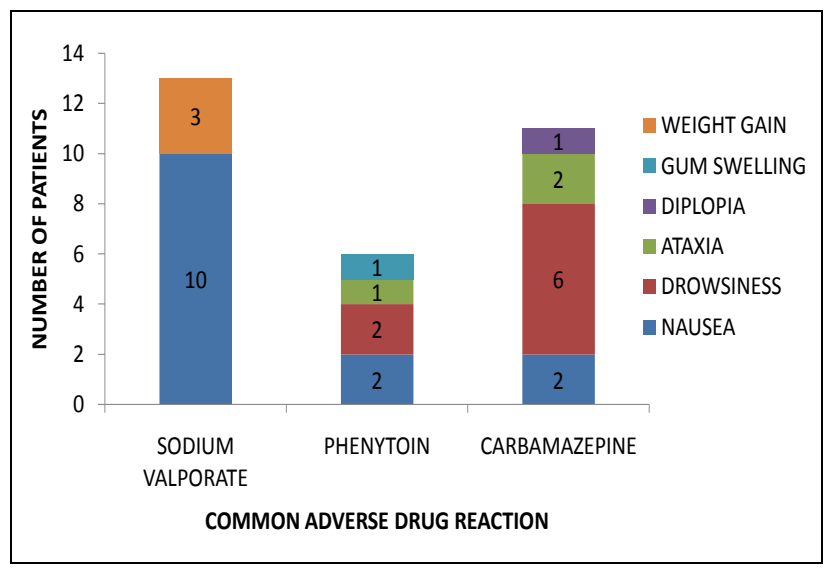

Figure 5: Adverse drug reactions with anti-epileptic drugs.

\section{DISCUSSION}

In this study, idiopathic generalized epilepsy was found to be the commonest type of epilepsy, with sodium valproate being the commonly prescribed drug in $66.33 \%$ of patients. These findings matched with the study done by Mathur S et al. where idiopathic generalized epilepsy was the commonest epilepsy. ${ }^{6}$ Symptomatic epilepsy was second commonest type of epilepsy $(30 \%)$ with phenytoin being the commonly prescribed drug in $60 \%$ of patients. Symtomatic epilepsy included seizures due to structural lesions of the brain such as stroke, cerebral bleed, trauma,cyst, tumour etc. The most common adverse drug reactions occurred with anti epileptic drugs were nausea and drowsiness. ${ }^{7}$ In patients of epilepsy at tertiary level hospital and found that anti epileptic drugs were prescribed 
as monotherapy in $62.12 \%$ and $68 \%$ of patients. ${ }^{8}$ In this study also anti epileptic drugs were prescribed as monotherapy in $59 \%$ of patients. The results of the present study revealed that the prescribing indicators in this study was 4.15 which was considered to be good as per rational drug prescribing. Good prescribing is advocated to avoid wastage of medicines and to avoid possible adverse effects. Also, prescribing unnecessary medications to patients increases cost of overall treatment. WHO highly recommends prescribing medications by generic name (NPN name) as a safety precaution for patients because these names are used uniformaly all over the world as per international agreement through WHO and allows better communication between health care providers. ${ }^{9}$ Our study also showed that there was more trend towards writing brand name of drugs rather than writing the generic name (NPN) of the drugs but this can only increase cost of treatment The mean percentage of drugs were prescribed by generic name in $25 \%$ of patients which was similar to the study done by Fattouh R in which drugs prescribed by generic name were $5.5 \% .^{10}$ In another study done by Naseeb TA there was also low mean percentage of drugs prescribed by generic names in $14.3 \%$ of patients. ${ }^{11}$ Further studies with large sample size are warranted so as to guide clinician towards rationale drug prescribing.

\section{ACKNOWLEDGEMENTS}

Authors would like to thank Dr. Kiran Bala for support in this study.

Funding: No funding sources

Conflict of interest: None declared

Ethical approval: The study was approved by the Institutional Ethics Committee

\section{REFERENCES}

1. How Common is Epilepsy in South-East Asia? Some facts and figures on Epilepsy. Available at: http://tinyurl.com/ngcl4bd.
2. Banerjee TK, Ray BK, Das SK. A longitudinal study of epilepsy in Kolkata, India. Epilepsia. 2010;51(12):2384-91.

3. Cloyd JC, Remmel RP. Antiepileptic drug pharmacokinetics and interactions: impact on treatment of epilepsy. Pharmacotherapy 2000;2(8):139-51.

4. Foletti GB. Clinical utilization of new anti-epileptic agents. Rev Med Suisse Romande 2000;120(9):703-7.

5. How to investigate drug use in health facilities: selected drug use indicators. Geneva, World Health Organization; 1993 (EDM Research Series No. 007).

6. Mathur S, Sen S, Ramesh L, Kumar S. Utilization pattern of antiepileptic drugs and their adverse effects, in a teaching hospital. Asian J Pharmaceut Clin Res. 2010;3(1):55-9.

7. George J, Jose J, Kulkarni DA, Hanamantappa RR, Shalavadi CV. Evaluation of Drug Utilization and Analysis of Anti-Epileptic Drugs at Tertiary Care Teaching Hospital. Indian Journal of Pharmacy Practice. 2016 Jul;9(3):189.

8. Meenakshi B. An analysis of prescription pattern and adverse drug reaction profile in children treated with antiepileptic drugs in a tertiary care teaching hospital. Int J Basic Clin Pharmacol. 2016;5(2):389-93.

9. Guidelines on the use of international nonproprietary names (INNs) for pharmaceutical substances. Geneva, World Health Organization, 1997.

10. Fattouh R, Hamad AB. Impact of using essential drug list: analysis of drug use indicators in Gaza Strip. East Mediterr Health J. 2010;16(8):886-92.

11. Naseeb TA, Nasser MA. Drug prescribing indicators in primary health care centers in Bahrain. Saudi Med J. 2005;26(9):1436-38.

Cite this article as: Narwat A, Sharma V.

Prescription pattern of antiepileptic drugs in indoor patients at tertiary care hospital in Haryana, India. Int J Basic Clin Pharmacol 2018;7:537-40. 